\title{
INFORMATION PRIVACY: CULTURE, LEGISLATION AND USER ATTITUDES
}

\section{Sophie Cockcroft}

\author{
Business School \\ University of Queensland \\ Brisbane, Australia \\ Email: s.cockcroft@business.uq.edu.au
}

\begin{abstract}
Information privacy has received much public and research interest in recent years. Globally this has arisen from public anxiety following the September 11 attacks and within Australia a progressive tightening of privacy legislation in particular the privacy amendment (private sector) Act of 2000 which became operative in 2001. This paper presents the results of a study into attitudes towards information privacy. Based on an instrument developed and validated by Smith et al (1996a) this study sets out to measure individual concerns regarding organisational use of information along four dimensions: collection, errors, unauthorised secondary use, and improper access. The survey was completed by 67 undergraduate and postgraduate students enrolled in an e-commerce security subject at the University of Queensland. Comparisons are drawn between the results of this study and an identical one carried out at the University of North Alabama. Whilst it is too early to draw conclusions about the impact of these attitudes on the success of e-commerce in general, the results should be of interest to those within universities seeking to expand the use of networking technologies for handling sensitive information such as enrolment and fee processing (Vanscoy \& Oakleaf 2003)
\end{abstract}

Keywords: IS Security, Information Policy, Managing IS

\section{INTRODUCTION}

Electronic commerce has become a reality the expansion of telecommunications capabilities has meant that the information age is upon us. This has made it easy for companies to gather and store vast amounts of consumer data. Whilst this can lead to competitive advantage for the firms concerned it heightens concerns over information privacy for the individual. This study aims to explore the level of concern regarding information privacy issues and to identify factors associated with possible differences in those attitudes. We compare results with a university based study at the University of North Alabama (UNA) (Alexander 1998). This study was chosen because it uses the raw, unaltered version of an instrument originally developed and validated by Smith, Milberg and Burke (1996a). It was also used in an earlier study by the same authors (Milberg et al. 1995). Many authors have since used the 15 question instrument as starting point for further research, but in these studies the instrument was adapted (Bellman et al. 2004a; Liu et al. 2004; Malhotra, Kim \& 
Agarwal 2004a; Smith, Milberg \& Burke 1996b). It measures participants' attitudes along four dimensions; collection, errors, improper access, and secondary use.

The paper is organised as follows. In the following section the theoretical framework of the study is laid down. Next, the research process is described. In the penultimate section the key findings are presented and compared with findings in the two earlier studies that used the same instrument. Finally the contributions of the study and suggestions for further work are explored.

\section{INFORMATION PRIVACY}

\section{Legal background}

In the past ten years there has been increasing global interest in privacy. Media attention has focussed people's attention on information privacy and their right to it (Henderson 1999). There are two broad means by which personal information privacy can be achieved; company self regulation, and government legislation. An appropriate level of privacy protection is essential for successful Ecommerce (Forder \& Quirk 2001). The European Union and the United States lie at two ends of the spectrum regarding their approaches. In the US the Clinton administration saw privacy concerns as a threat to the development of e-commerce. It considered that private industry working in cooperation with consumer groups was preferable to government regulation (Culnan 2000). Europe has taken a much more hands on approach with the passing of the EU directive on privacy that came into effect in 1998 (EU 1998). This directive established minimum standards for processing and use of personal data. In Australia the Privacy act of 1988 applied only to federal government agencies. There was a long period in which state and federal governments have been uncertain whether to introduce legislation that applies to the public and private sectors. This uncertainty was resolved in 1999 when the privacy amendment act (private sector) was proposed. This came into force in December 2001 (Australian Privacy Commissioner 2000). Given that e-commerce has to occur in a global environment, these differing approaches can cause some conflict, and have the potential to hinder the smooth running of commercial operations. It is imperative that there is cooperation between citizens, merchants and governments of different nations. A full examination of the legal implications of assuring privacy is beyond the scope of this paper. It is the role of citizens in this three-way cooperation that is of interest here.

The main aim is to take a closer look at individuals' privacy concerns, and to contribute to the body of research that informs regulation, both self and governmental. A key feature of the study is the use of a validated instrument, which makes the results readily comparable to past and future studies.

Like the previous study mentioned, (Alexander 1998), this study uses students as its subject. Whilst the results of this study may not necessarily be generalised to the population as a whole, they are likely, at the least, to be of interest to system developers and policy makers within the university setting. Records maintained by universities are, by their nature and by law, private. However universities are increasingly expected to provide access to information through networking technologies these include systems for managing enrolment, grades and payment of fees. For example at the University of Queensland a system called SI-Net that supports these activities is undergoing an extensive upgrade (Student Systems Group 2006). Initiatives such as these heighten the need for vigilance regarding the security of these records. 


\section{The role of social and demographic factors}

Researchers in this area have identified a number of factors influencing individual's attitudes to information privacy. In particular frequency of use has been associated with lower levels of concern about privacy issues, and less experience with higher levels of anxiety (reported in (Alexander 1998)). Researchers have also explored the effects of gender, age and personality type on attitudes to information privacy (Vance 2000). Of interest in Australia was the Roy Morgan Poll which found that younger Australians (14-24) were least fearful, and women were more inclined to be worried about privacy issues (Roy Morgan 1999). Culnan (1993) made a particular study of secondary information use which she defined as

"the use of personal information for other purposes subsequent to the original transaction between an individual and an organization when the information was collected".

The key finding of this study was that concern over secondary use was correlated with the level of control the individual has over the secondary use. This type of control is exemplified by American Express, which agreed to inform its customers that it tracked their buying habits and used the data to compile mailing lists, which it sold to other companies. American Express further agreed to notify card holders of their ability to "opt out" of such lists (Crenshaw 1992) in (Culnan 1993) .

Milberg et al (1995) investigated cultural influences on attitudes to privacy amongst members of the Information Systems Audit and Control Associations in a number of countries. One of their key findings was that lower levels of privacy concern were associated with countries with no privacy regulation and in countries which have the highest level of government involvement in corporate privacy management. This is a complex relationship indicating that where there is little awareness there is little concern and increasing levels of concern result in increasing legislation to the point where concern again drops off. In order to classify the level of government involvement in corporate privacy management they developed the scale illustrated in Figure 1. Australia was placed in the middle of the scale under Data Commissioner, and the US was placed lower down the scale under Voluntary control.

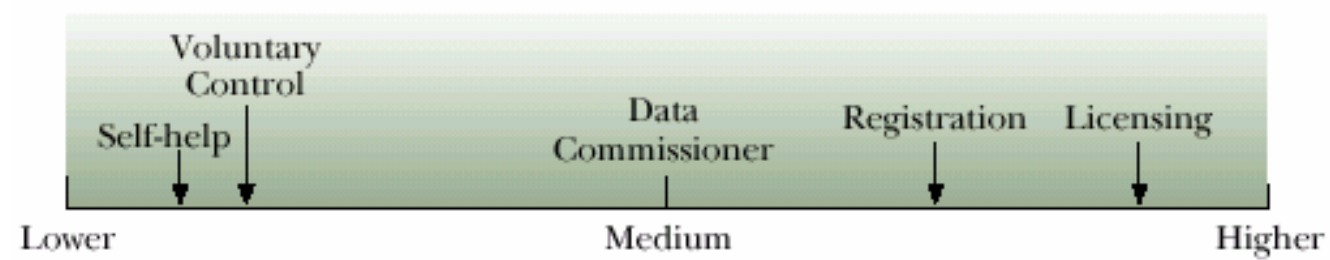

Figure 1 Level of Government Involvement in Corporate Privacy Management (Milberg et al. 1995) p66

The studies mentioned in the first two paragraphs are hard to compare because they all used different instruments and reviewed different dimensions. The following section explains how some of the factors identified in earlier studies were tested, and how comparisons were made with studies using the same instrument. 


\section{RESEARCH METHOD}

The survey is based on a parsimonious 15 question instrument developed by Smith, Milberg and Burke (1996a):

\section{Table 1. Final Instrument}

Here are some statements about personal information. From the standpoint of personal privacy. please indicate the extent to which you, as an individual, agree or disagree with each statement by circling the appropriate number.*

A. It usually bothers me when companies ask me for personal information.

B. All the personal information in computer databases should be double-checked for accuracy-no matter how much this costs.

C. Companies should not use personal information for any purpose unless it has been authorized by the individuals who provided the information.

D. Companies should devote more time and effort to preventing unauthorized access to personal information.

E. When companies ask me for personal information, I sometimes think twice betore providing it.

F. Companies should take more steps to make sure that the personal information in their files is accurate.

G. When people give personal information to a company for some reason, the company should never use the information for any other reason.

H. Companies should have better procedures to correct errors in personal information.

I. Computer databases that contain personal information should be protected from unauthorized access-no matter how much it costs.

J. It bothers me to give personal information to so many companies.

K. Companies should never sell the personal information in their computer databases to other companies.

L. Companies should devote more time and effort to verifying the accuracy of the personal information in their databases.

M. Companies should never share personal information with other companies unless it has been authorized by the individuals who provided the information.

N. Companies should take more steps to make sure that unauthorized people cannot access personal information in their computers.

O. I'm concerned that companies are collecting too much personal information about me.

Items A, E, J, and O comprise the "Collection" subscale; items B, F, H, and L comprise the "Errors" subscale; items C, G, K, and M comprise the "Unauthorized Secondary Use" subscale; and items D, I, and $\mathrm{N}$ comprise the "Improper Access" subscale. Subscale scores are calculated by averaging the responses to the items for each subscale; an overall score is then calculated by averaging the subscale scores.

Figure 2 Survey questions (Smith, Milberg \& Burke 1996a, p170)

The survey was made available to the 100 students of a postgraduate subject "Securing the Commercial Internet" and the 70 students in the undergraduate subject of the same name. There 
were 52 valid responses in the postgraduate subject giving a response rate of $52 \%$ and 15 in the undergraduate subject giving a response rate of $21 \%$ and an overall response rate of $39 \%$. There were 30 women in the survey and 36 men and one person did not state their gender In the sample there were 34 students who identified themselves as being of Asian origin, 19 who identified themselves as European/Australian and 14 who did not state their race/ethnicity. The survey was delivered via WebCT, which has built in survey software that ensures the responses are anonymous. Ethical approval was granted and students were given and overview of the project and assured that their participation in no way related to the marks for the course, and that they could withdraw at any time. Following this a consent form was signed.

In addition to the questions shown in Figure 2, further questions were asked about demographics and other background factors described below that are often associated with attitudes to privacy. The supplementary questions selected here, followed those of Alexander (1998) who carried out a comparable university based study and related to skill level, and work environment. The questionnaire measures participants' attitudes along four dimensions, as illustrated in Figure 3:

\section{Collection}

These questions deal with concerns about the volume of data being collected and the reasons for its collection. The "Collection" subscale is made up of questions A,E,J and O shown in Figure 2. It is reflected in principle 1 of the 10 privacy principles outlined in the Australian privacy amendment act (Office of the Privacy Commissioner 2000) “An organisation must not collect personal information unless the information is necessary for one or more of its functions or activities. An organisation must collect personal information only by lawful and fair means and not in an unreasonably intrusive way”.

\section{Errors}

Questions B,F,H and L of Figure 2 make up the "Errors" subscale. These questions examine participants' attitudes towards errors, both accidental and maliciously planted, and the steps companies should take to avoid them. When an organization holds information about its customers it should allow them to find out what that information is, and contest its accuracy and completeness if they believe it is wrong. This is the underlying premise of the access/correction principle, another of the 10 privacy principles outlined in the Australian privacy amendment act (Office of the Privacy Commissioner 2000).

\section{Improper access}

The questions on improper access probe participants' attitudes to who has access to their information within the organisation that collects and stores it. The improper access subscale measured by questions $\mathrm{D}$, I and $\mathrm{N}$ reflects the principle of data security from the Australian privacy amendment act which states that an organisation must take reasonable steps to protect the personal information it holds from misuse and loss and from unauthorised access, modification or disclosure.

\section{Secondary use}

These questions relate to the common practice of using data for purposes other than those for which it was collected. E.g collecting it for research and using it for marketing, or collecting data in the course of normal credit card transactions and using it for marketing. In an Australian context this is 
directly related to principle 2 of the privacy amendment act, use and disclosure, and measured by items $\mathrm{C}, \mathrm{G}, \mathrm{K}$ and $\mathrm{M}$ in the instrument.

\section{RESEARCH PROPOSITIONS}

The analysis was conducted in two parts. First, comparisons were made between the results of this study, and two previous studies that used the same instrument. Second with reference to the literature review above, six factors were identified which have been shown to have an effect on attitudes to privacy. These are illustrated in Figure 3 and the relevant research propositions are identified below. These factors were tested using one-way ANOVA.

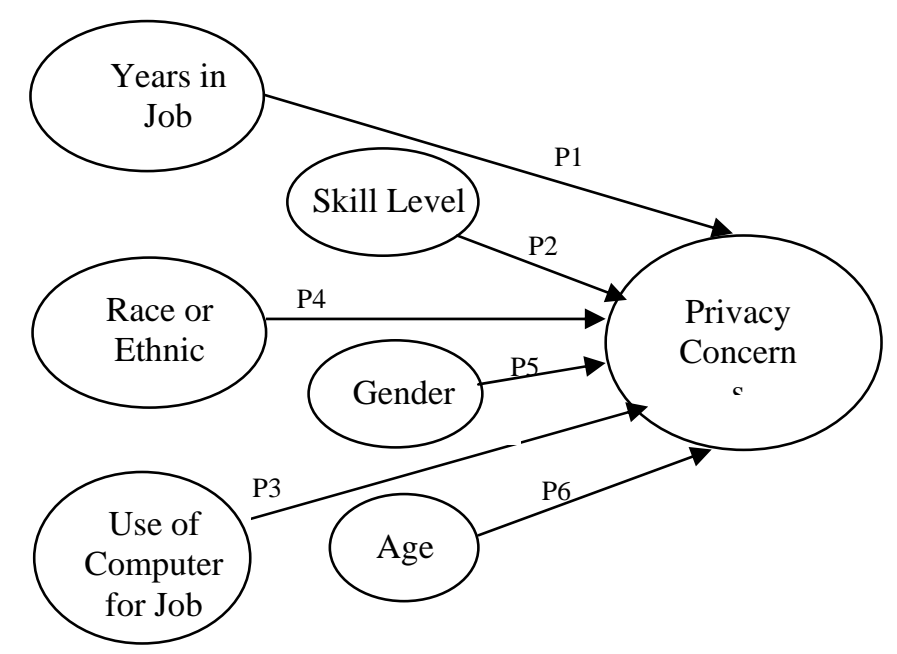

Figure 3: Factors proposed to be associated with privacy concerns

\section{Research propositions}

A number of authors have proposed a negative relationship between years of work, and use of a computer at work, and levels of privacy concern (Alexander 1998; Vance 2000). Another common finding is that more experienced internet users will have lower levels of privacy concern (Bellman et al. 2004b; Rose 2006). Rose (2006), for example, found that those who had used the internet for more than 4 years had significantly lower levels of concern for internet privacy. This leads to the first three proposals;

P1 More years at work is negatively associated with high levels of privacy concern,

P2 Self-reported skill level will be negatively associated high levels of privacy concern (Alexander 1998),

P3 Use of a computer at work will be negatively associated with high levels of privacy concern (Alexander 1998; Vance 2000). 
Studies are emerging that explore the influence of national culture on attitudes to information privacy (Dinev \& Hart 2004; Heales \& Cockcroft 2005; Rose 2006). In the context of government surveillance Dinev et al. (2006) found that Italians had less concern for information privacy than consumers in the US. In the current study, data collection did not take a fine grained approach to culture, participants were simply asked their race or ethnic origin amongst the demographic questions similar to earlier studies (Milberg et al. 1995; Whitman, Townsend \& Hendrickson 1999). The concept of culture, and its relationship to attitude to information privacy, is an area that requires further research, however for this analysis it is proposed that:

P4 Race or ethnic origin significantly affects levels of privacy concern.

National polls conducted in Australia, both before and after the introduction of the privacy amendment act, suggested that gender was significant in users' concern for information privacy (Morgan 1999; Office of the Privacy Commissioner 2004). More recently some marketing studies have found that women have perceptions of greater risk in online transactions than do men (Garbarino \& Strahilevitz 2004) and more concern about information privacy (Phillip \& Suri 2004). Thus it is proposed:

P5 Gender significantly affects levels of privacy concern.

Several authors have found a negative correlation between age and privacy concern noting that older internet users show a higher level of concern (Rose 2006) (Heales \& Cockcroft 2005). This led to the proposition that:

P6 Age is negatively associated with high levels of privacy concern. (Morgan 1999)

\section{FINDINGS}

The findings of this study are addressed under three headings, first in comparison to the Alabama study, second with the 1995 Milberg study and finally in terms of testing the research propositions identified.

\section{Comparison with Alabama study}

Table 1 shows the attitudes of students in this survey as compared to business students at the University of Alabama (UNA). University of Queensland (UQ) students illustrate higher levels of concern in all dimensions. 


\begin{tabular}{|c|c|c|c|c|c|c|c|c|}
\hline & \multicolumn{2}{|c|}{$\begin{array}{l}\text { Undergraduate UQ } \\
\text { N=15 }\end{array}$} & \multicolumn{2}{|c|}{$\begin{array}{c}\text { Postgraduate UQ } \\
\quad \mathrm{N}=52\end{array}$} & \multicolumn{2}{|c|}{$\begin{array}{c}\text { Overall UQ } \\
\mathrm{N}=67\end{array}$} & \multicolumn{2}{|c|}{$\begin{array}{c}\text { Overall UNA } \\
\mathrm{N}=124\end{array}$} \\
\hline Errors & $\begin{array}{c}\text { Mean } \\
6.00\end{array}$ & $\begin{array}{c}\text { Std. Dev. } \\
0.74\end{array}$ & $\begin{array}{c}\text { Mean } \\
5.35\end{array}$ & $\begin{array}{c}\text { Std. Dev. } \\
1.03\end{array}$ & $\begin{array}{l}\text { Mean } \\
5.50\end{array}$ & \begin{tabular}{|c} 
Std. Dev. \\
1.00
\end{tabular} & $\begin{array}{c}\text { Mean } \\
5.51\end{array}$ & $\begin{array}{c}\text { Std. Dev. } \\
1.15\end{array}$ \\
\hline $\begin{array}{l}\text { Secondary } \\
\text { Use }\end{array}$ & 6.63 & 0.52 & 6.28 & 0.84 & 6.36 & 0.79 & 6.1 & 1.24 \\
\hline $\begin{array}{l}\text { Improper } \\
\text { Access }\end{array}$ & 6.36 & 0.84 & 6.04 & 0.96 & 6.11 & 0.94 & 6.03 & 1.25 \\
\hline Collection & 5.50 & 1.18 & 5.41 & 0.84 & 5.43 & 0.92 & 4.59 & 1.3 \\
\hline OVERALL & 6.10 & 0.55 & 5.79 & 0.66 & 5.86 & 0.64 & 5.56 & 0.99 \\
\hline
\end{tabular}

Table 1 Comparison with Alabama study

It will be noted that American students are generally less concerned about privacy which fits with the Milberg study described earlier (Milberg et al. 1995). In addition postgraduate students appear to be less concerned about privacy than undergraduate students on all dimensions except collection. This is illustrated in figure 2:

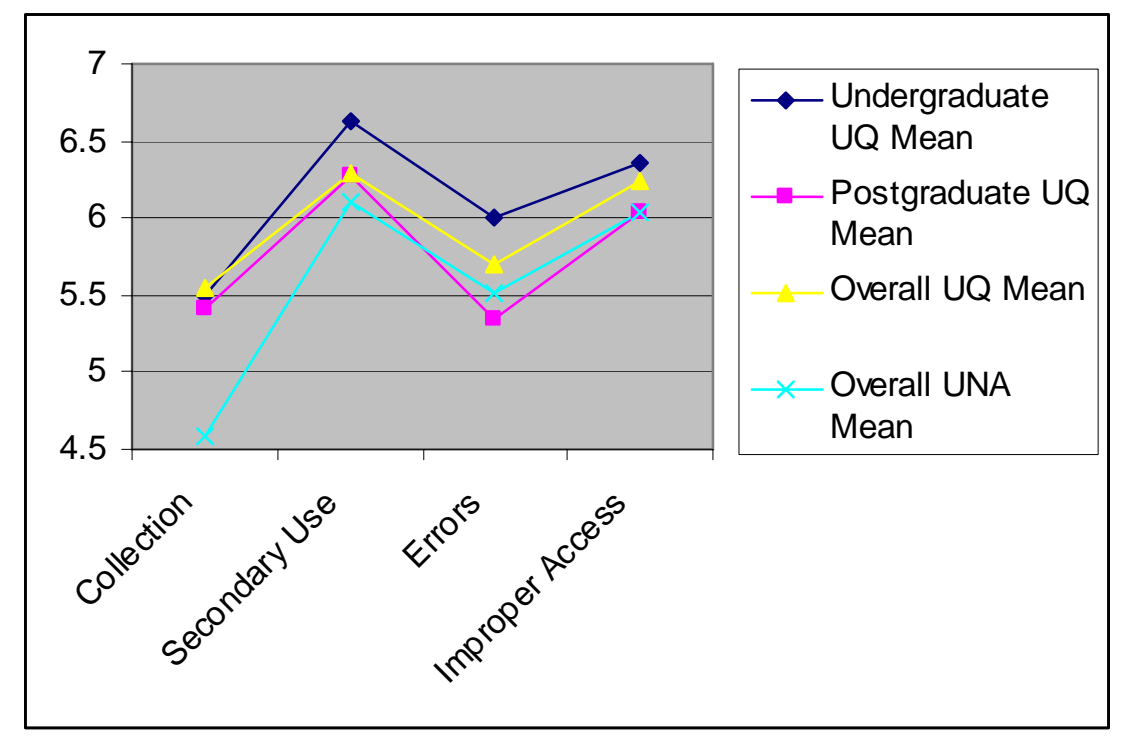

Figure 2 Privacy concerns among business student at UNA and E-commerce Students at UQ

The original table in Milberg et al (1995), on which Table 2 is based, served to support the hypothesis in that levels of concern are lower at each end of the governmental regulatory scale illustrated in Figure 1 and higher in the middle. In this adapted table, countries are listed top-down in the order of government involvement. Australia, Canada and New Zealand are in the middle ground. 


\begin{tabular}{|l|c|c|c|c|}
\hline & Collection & Secondary Use & Errors & Improper Access \\
\hline Thailand & $4.7(4)$ & $5.8(2)$ & $5.2(3)$ & $6(1)$ \\
\hline France & $5(4)$ & $6.6(1)$ & $5.5(3)$ & $6.2(2)$ \\
\hline Japan & $4.9(4)$ & $6.3(2)$ & $5.6(3)$ & $6.5(1)$ \\
\hline United States & $5.4(4)$ & $6.1(1)$ & $5.5(3)$ & $5.9(2)$ \\
\hline United States (UNA) & $4.59(4)$ & $6.10(1)$ & $5.51(3)$ & $6.03(2)$ \\
\hline Australia & $5.6(3)$ & $6.6(1)$ & $5.3(4)$ & $5.8(2)$ \\
\hline Australia (UQ) & $5.43(4)$ & $6.36(1)$ & $5.50(3)$ & $6.11(2)$ \\
\hline Canada & $5.7(4)$ & $6.4(1)$ & $5.6(3)$ & $6.1(2)$ \\
\hline New Zealand & $5.3(3)$ & $6.4(1)$ & $5.2(4)$ & $5.9(2)$ \\
\hline Denmark & $4.8(4)$ & $6.2(1)$ & $5.5(3)$ & $6.1(2)$ \\
\hline United Kingdom & $5.2(4)$ & $6(1)$ & $5.6(3)$ & $5.8(2)$ \\
\hline
\end{tabular}

Table 2 Level of information privacy concern by dimension in countries (adapted from (Milberg et al. 1995)) First number represents the mean on a scale of 1-7 the number in parentheses represents the dimensions rank in a given country.

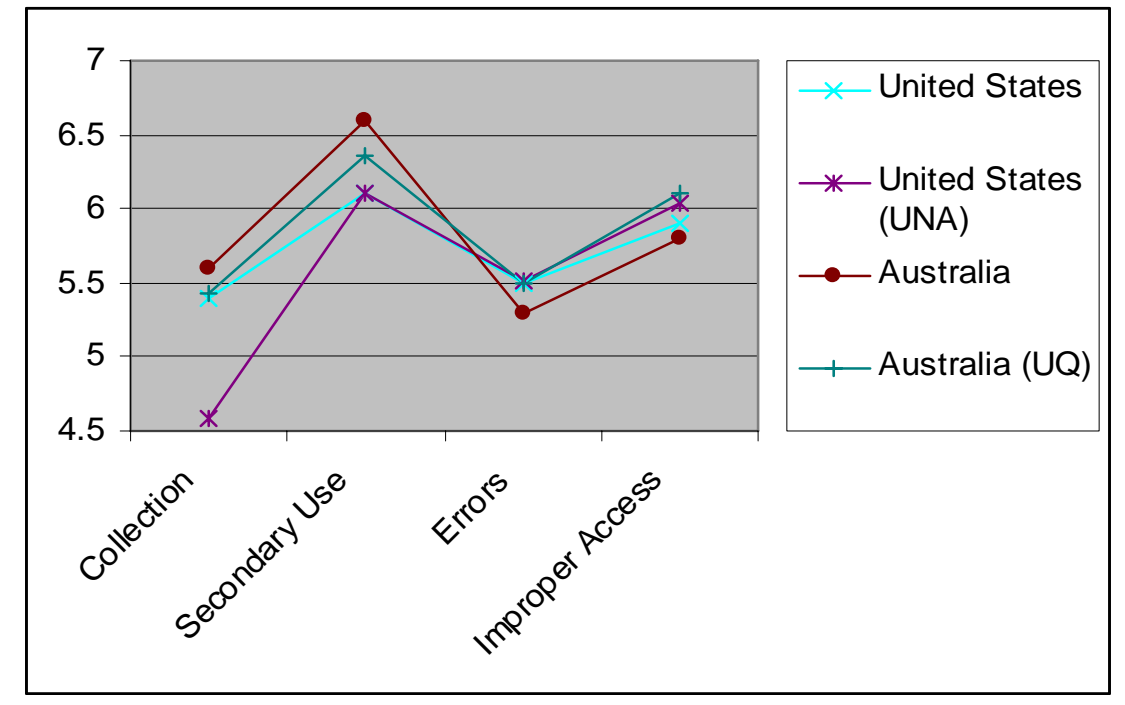

Figure 3. Australian and US attitudes to privacy. Mainstream data taken from (Milberg et al. 1995). Student data taken from (Alexander 1998) at the University of North Alabama and the current study.

The University of Queensland students go against their national trend in terms of how the concerns are ranked. American students, as expected, appear to be less concerned about privacy than Australian students. It is hard to judge the significance of this without further study of the make up of these student groups, as we will see the UQ group was far from homogenous. The highlighted part of the table is illustrated graphically in Figure 3. 


\section{Testing of research propositions}

The six propositions identified were tested using analysis of variance (see Appendix). P1 was partially accepted. Years at work positively correlated with privacy concerns over improper access. P2 was rejected. Those reporting a higher level of skill were not significantly less concerned about privacy. P3 was rejected because the significance was in the opposite direction than expected, i.e. use of a computer at work was positively correlated with privacy concerns in one dimension. Those that use a computer at work are more likely to be concerned about improper access. P4 was rejected; there was no relationship between race and privacy concerns. P5 was rejected; gender had no effect on privacy concerns. P6 was accepted in one dimension age is a significant factor in concerns about improper access. Of the hypotheses that were accepted, there were no significant two way effects between age, years at work and use of a computer at work.

\section{DISCUSSION}

The U.S. and Europe exhibit very different approaches to information privacy from both regulatory and managerial perspectives. It seems that these differences are grounded in different cultural values and assumptions about the meaning of privacy (a "human rights" issue in Europe versus a contractual issue in the U.S.). Australia falls between the two.

This study supports earlier work in that the students in this study exhibited levels of privacy concern appropriate to the cultural setting within which they find themselves, i.e. Australia. A closer examination of the make up of the class brings into focus one of the limitations of the study. Two thirds of the sample is of Asian decent, and it is impossible to tell whether this will affect their attitudes since those who were brought up in Asia cannot be distinguished from those who are born or naturalized Australians. The crude division of Asian vs. non-Asian is not reliable since the data was gathered with a free-text field and respondents entered a variety of answers. If we stick with this division a further findings emerges. Students of Asian origin are less concerned about privacy than those of non-Asian origin.

The two other key findings were that those who used a computer at work were more likely to be concerned about collection - this probably reflects a high level of concern relating to a broader class of data than just their own personal data. It likely represents concerns relating to the management of data in a work setting in general and possibly the data they personally collect and how it is stored.

A further interesting and possibly confounding factor is that these students were at the start of a required course in security in e-commerce. This could have resulted in heightened awareness of privacy and security in general. One aim of this study was to provide the students with an opportunity to examine their own values and concerns in relation to privacy.

One limitation of the work is that whilst a number of studies have used the 15 question instrument developed by Smith Milberg and Burke or adaptations thereof(Bellman et al. 2004b; Liu et al. 2004; Malhotra, Kim \& Agarwal 2004b; Smith, Milberg \& Burke 1996a). Recently it has been suggested that CFIP may be more parsimoniously represented as a higher-order factor than a correlated set of first-order factors(Malhotra, Kim \& Agarwal 2004b; Stewart \& Segars 2002). Further work in this area should proceed in cognisance of this new understanding.

This study contributes to the body of knowledge in the area of consumer privacy; it identifies information practices that have the potential cause public concern along predefined dimensions and 
particularly in an Australian context. Firms can use this information to self-regulate and develop and promulgate proactive privacy policies as opposed to fielding complaints in reactive mode.

\section{APPENDIX}

\begin{tabular}{|c|c|c|c|c|}
\hline \multicolumn{5}{|c|}{ Improper Access } \\
\hline \multicolumn{2}{|c|}{ Coefficients: } & Estimate & Std.Error & t value $\operatorname{Pr}(>|t|)$ \\
\hline (Intercept) & 3.22065 & 1.17987 & 2.730 & 0.00878 \\
\hline age & 0.02232 & 0.02582 & 0.864 & 0.39166 \\
\hline compjob & 0.24866 & 0.10595 & 2.347 & $0.02301 *$ \\
\hline skilllev & 0.12498 & 0.14069 & 0.888 & 0.37870 \\
\hline gender & 0.13328 & 0.25892 & 0.515 & 0.60903 \\
\hline newrace & 0.03028 & 0.04430 & 0.684 & 0.49740 \\
\hline yearsjob & -0.05681 & 0.03442 & -1.651 & 0.10523 \\
\hline \multicolumn{5}{|l|}{--} \\
\hline \multicolumn{5}{|c|}{$* p<.05$} \\
\hline \multicolumn{5}{|c|}{ Residual standard error: 0.8621 on 49 degrees of freedom } \\
\hline \multicolumn{5}{|c|}{ Multiple R-Squared: 0.1959, Adjusted R-squared: 0.09743} \\
\hline \multicolumn{5}{|c|}{ F-statistic: 1.99 on 6 and 49 DF, p-value: 0.08516} \\
\hline \multicolumn{2}{|c|}{ Coefficients: } & Estimate & Std.Error & t value $\operatorname{Pr}(>|t|)$ \\
\hline (Intercept) & 4.46836 & 0.64955 & 6.879 & $7.06 \mathrm{e}-09$ \\
\hline compjob & 0.28076 & 0.09852 & 2.850 & $0.00622 * *$ \\
\hline yearsjob & -0.03682 & 0.02401 & -1.533 & 0.13111 \\
\hline \multicolumn{5}{|l|}{--} \\
\hline \multicolumn{5}{|c|}{$* * p<.01$} \\
\hline \multicolumn{5}{|c|}{ Residual standard error: 0.8463 on 53 degrees of freedom } \\
\hline \multicolumn{5}{|c|}{ Multiple R-Squared: 0.1619, Adjusted R-squared: 0.1302} \\
\hline \multicolumn{5}{|c|}{ F-statistic: 5.118 on 2 and 53 DF, $p$-value: 0.009283} \\
\hline \multicolumn{5}{|c|}{ Secondary Use } \\
\hline \multicolumn{2}{|c|}{ Coefficients: } & Estimate & Std.Error & t value $\operatorname{Pr}(>|t|)$ \\
\hline (Intercept) & 4.10130 & 0.99648 & 4.116 & 0.000147 \\
\hline age & 0.04479 & 0.02181 & 2.054 & $0.045332 *$ \\
\hline compjob & 0.08946 & 0.08948 & 1.000 & 0.322332 \\
\hline skilllev & 0.04340 & 0.11882 & 0.365 & 0.716480 \\
\hline gender & 0.30027 & 0.21868 & 1.373 & 0.175969 \\
\hline newrace & 0.00186 & 0.03741 & 0.050 & 0.960548 \\
\hline yearsjob & -0.04145 & 0.02907 & -1.426 & 0.160215 \\
\hline \multicolumn{5}{|l|}{--} \\
\hline \multicolumn{5}{|c|}{$* p<.05$} \\
\hline \multicolumn{5}{|c|}{ Residual standard error: 0.7281 on 49 degrees of freedom } \\
\hline \multicolumn{5}{|c|}{ Multiple R-Squared: 0.1375, Adjusted R-squared: 0.03183} \\
\hline F-statistic: & 1.301 on 6 & $49 \mathrm{DF}, p-$ & ue: 0.2743 & \\
\hline
\end{tabular}




\section{REFERENCES}

Alexander, P 1998, 'Attitudes Toward Information Privacy: Differences Among and Between Faculty and Students', paper presented to The AIS Americas Conference, Baltimore, Maryland, August 14-16, 1998.

Australian Privacy Commissioner 2000, Privacy and the private sector, Australian Government, viewed 21/05/2001 2001, <http://www.privacy.gov.au/>.

Bellman, S, Johnson, EJ, Kobrin, SJ \& Lohse, GL 2004a, 'International differences in information privacy concerns: A global survey of consumers', Information Society, vol. 20, no. 5, pp. 313-24.

---- 2004b, 'International differences in Information Privacy Concerns: A Global Survey of Consumers', The Information Society, vol. 20, pp. 313-24.

Culnan, MJ 1993, ' 'How did they get my name?': An exploratory investigation of consumer attitudes toward secondary information use', MIS Quarterly, vol. 17, no. 3, pp. 341-62.

---- 2000, 'Protecting Privacy Online: Is self regulation working?' Journal of Public Policy and Marketing, vol. 19, no. 1, pp. 20-6.

Dinev, T, Bellotto, M, Hart, P, Russo, V, Serra, I \& Colautti, C 2006, 'Internet users' privacy concerns and beliefs about government surveillance: An exploratory study of differences between Italy and the United States', Journal of Global Information Management, vol. 14, no. 4, pp. 57-93.

Dinev, T \& Hart, P 2004, 'Internet privacy concerns and their antecedents - measurement validity and a regression model', Behaviour \& Information Technology, vol. 23, no. 6, pp. 413-22.

EU 1998, EU directive on personal data protection enters into effect, viewed 21/5/04 2004, $<$ http://www.eurunion.org/news/press/1998-4/pr89-98.htm>.

Forder, J \& Quirk, P 2001, Electronic Commerce and the Law, 1 edn, Wiley, Brisbane.

Garbarino, E \& Strahilevitz, M 2004, 'Gender differences in the perceived risk of buying online and the effects of receiving a site recommendation', Journal of Business Research, vol. 57, no. 7, pp. 768-75.

Heales, J \& Cockcroft, S 2005, 'National Culture, Trust and Internet Privacy Concerns', paper presented to 16th Australasian conference on Information Systems, Sydney, 29 November 2 December.

Henderson 1999, 'Personal Information privacy: implications for MIS managers', Information and Management, vol. 36, pp. 213-20.

Liu, C, Marchewka, JT, Lu, J \& Yu, CS 2004, 'Beyond concern: a privacy-trust-behavioral intention model of electronic commerce', Information \& Management, vol. 42, no. 1, pp. 127-42.

Malhotra, NK, Kim, SS \& Agarwal, J 2004a, 'Internet users' information privacy concerns (IUIPC): The construct, the scale, and a causal model', Information Systems Research, vol. 15, no. 4, pp. 336-55.

---- 2004b, 'Internet users' information privacy concerns (IUIPC): Tthe construct, the scale, and a causal model', Information Systems Research, vol. 15, no. 4, pp. 336-55. 
Milberg, S, Burke, S, Smith, J \& Kallman, E 1995, 'Values, personal information, privacy and regulatory approaches', Communications of the Acm, vol. 38, no. 12, pp. 65-74.

Morgan, R 1999, Big Brother Bothers Most Australians, Roy Morgan, viewed 15 October 2006 2006, <http:/www.roymorgan.com/news/polls/1999/3221/>.

Office of the Privacy Commissioner 2000, National Privacy Principles (Extracted from the Privacy Amendment (Private Sector) Act 2000), viewed October 13 2006, <http://www.privacy.gov.au/publications/npps01.html>.

---- 2004, Community attitudes toward privacy 2004, Roy Morgan Research, Sydney.

Phillip, MV \& Suri, R 2004, 'Impact of gender differences on the evaluation of promotional emails', Journal of Advertising Research, vol. 44, no. 4, pp. 360-8.

Rose, EA 2006, 'An examination of the concern for information privacy in the New Zealand regulatory context', Information \& Management, vol. 43, no. 3, pp. 322-35.

Smith, J, Milberg, S \& Burke, S 1996a, 'Information Privacy: Measuring Individuals' Concerns about Organisational Practices', MIS Quarterly, vol. June, no. 2, pp. 167-96.

---- 1996b, 'Information Privacy: Measuring Individuals' Concerns about Organisational Practices', MIS Quarterly, vol. June, pp. 167-96.

Stewart, KA \& Segars, AH 2002, 'An empirical examination of the concern for information privacy instrument', Information Systems Research, vol. 13, no. 1, pp. 36-49.

Student Systems Group 2006, Welcome to mySI-net, University of Queensland, viewed 21/10/06 2006, <http://www.uq.edu.au/sinet-support/>.

Vance, DA 2000, 'On the effects of exogenous and endogenous variables on information privacy concerns: a preliminary comparative study', paper presented to Challenges of Information Technology Management in the 21st Century. 2000 Information Resources Management Association International Conference., Hershy.

Vanscoy, A \& Oakleaf, M 2003, 'Online Privacy vs. Enhanced Virtual Reference: What do Patrons Really Want?' paper presented to ACRL Eleventh National Conference, Charlotte, North Carolina, April 10.13, 2003.

Whitman, ME, Townsend, AM \& Hendrickson, AR 1999, 'Cross-national differences in computeruse ethics: A nine- country study', Journal of International Business Studies, vol. 30, no. 4, pp. 673-87. 


\section{THE AUTHOR}

Sophie Cockcroft is a member of the information systems group at the University of Queensland Business School. Her primary research interests relate to data quality, integrity control, and data modelling specifically in the application areas of geographic and medical information systems. More recently she has been looking at the effects of National Culture on attitudes to Information privacy and software development. Her publications have appeared in the Information and Software Technology, Journal of Global Information Technology Management, and GeoInformatica. She teaches courses relating to information systems development, including analysis and design of electronic commerce and www applications and security. Sophie has previously been an academic at City University, Hong Kong and Otago University, New Zealand. Prior to becoming an academic, Sophie worked in accountancy and as a computing geologist at BP

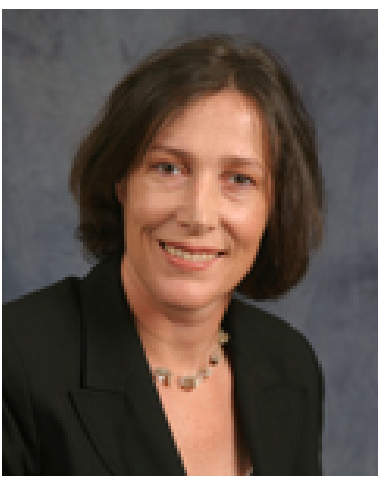
Exploration in London. 